\title{
A New Management Protocol for Lowering the Rate of Distal Penile Hypospadias Fistula
}

\author{
NABIL SHAFTER, M.Sc.; WEAL SAAD ELDEEN, M.D. and MAHMOUD ELOTEIFY, M.D. \\ The Department of Plastic Surgery, Faculty of Medicine, Assiut University Hospitals, Assiut, Egypt
}

\begin{abstract}
Introduction: Hypospadias is a common congenital defect thought to be caused by incomplete fusion of the urethral folds, resulting in a proximally located urethral meatus anywhere from the glans to the perineum.
\end{abstract}

Patients and Methods: Prospective study constitutes $(\mathrm{n}=65)$ patients with distal penile hypospadias was repaired by Snodgrass technique and modified Snodgrass technique between a period from (July 2013 to June 2015) to lowering the of fistula complication after hypospadias repair. The mean of age of Snodgrass group is $7.1 \pm 3.62$ (to 17 years in ages) and $6 \pm 4.3$ ( 2 to 23 years) in modified Snodgrass group.

Results: Four patients $(6.15 \%)$ had developed urethrocutaneous fistula from the total of cases, and fistula rate in modified Snodgrass group was better than Snodgrass group as the follow: $(\mathrm{n}=2$ patients $4 \%$ ) in modified Snodgrass group and $(\mathrm{n}=2$ patients $13.3 \%)$ in Snodgrass group.

Conclusion: The complications edema, infection, hemorrhage, catheter obstruction and fistula formation in modified Snodgrass group was less than Snodgrass group.

Modified Snodgrass group is better than the Snodgrass group to lowering the rate of fistula complication.

Key Words: Hypospadias - Modification snodgrass - Fistula.

\section{INTRODUCTION}

Hypospadias is the most common congenital anomaly of the penis, affecting $0.4-8.2$ of 1000 live male babies [1].

The term hypospadias stems from two Greek words: Hypo, which means "below," and spadon, which means "hole". The anomaly is characterized by a urethral meatus ectopically located proximal to the normal place on the ventral side of the penis. Different anatomic presentations can be observed. The position of the urethral meatus can be classified as anterior or distal (glandular, coronal, or subcoronal; $60-65 \%$ of cases), middle (mid penile; $20-$ $30 \%$ of cases), or posterior or proximal (posterior penile, penoscrotal, scrotal, or perineal; $10-15 \%$ of cases) [2]. The subcoronal position is the most common. Proximal cases are considered severe and can be associated with chordee [2].

Three main features characterize hypospadias (a ventral position of the meatus, a dorsal hooded skin and a ventral curvature on erection [3].

Hypospadias can be repaired in a single-stage operation that includes meataladvancement and glanuloplasty (MAGPI), glans approximation procedure, and tubularization following incision of the urethral plate (TIP) [4].

The authors tried to identify actual international trends in the management of hypospadias by inviting pediatric urologists, pediatric surgeons, urologists, and plastic surgeons worldwide to participate in an anonymous multiple-choice online questionnaire. Completed questionnaires were obtained from 377 participants from 68 countries. From the results, it appeared that in distal hypospadias (subcoronal to midshaft), TIP repair was the preferred method of 52.9-71.0\% of participants. MAGPI was the preferred method to correct glandular hypospadias. The two-stage repair was the preferred method to correct proximal hypospadias for 43.3$76.6 \%$ of participants, which is in contrast to the results of the North American survey in which onestage procedure was the method of choice [5].

Surgery to reconstruction hypospadias has a history of more than 150 years. To date more than 300 surgical procedures with accompanying variation have been proposed for the repair of hypospadias. Such reconstruction should be simple, easily learned, applicable to the majority of cases, completed in a single stage and resulting in pleasing cosmetic result with a low complication rate [6].

Snodgrass described the tubularised incised plate (TIP) for repair of hypospadias in 1994 as a 
mean to widen and improve mobilization of the urethral plate when performing a Thiersch-Duplay urethroplasty [7].

Since that time many reports have been published describing the success of this modified procedure to repair distal hypospadias lesions [8,9].

Fistula formation is the commonest complication after hypospadias repair [10].

To avoid fistulae after hypospadias repair Yutaro et al., recommend the use of scrotal dartos flap as a well vascularized and long flap to envelop the neourethra after TIP operation for the prevention of the urethrocutaneous fistula [11].

\section{PATIENTS AND METHODS}

Prospective study constitutes (65) patients with distal penile hypospadias was repaired by Snodgrass technique and modified Snodgrass techniquebetween a period from (July 2013 to June 2015) to lowering the of fistula complication after repair who presented to Assuit University Hospital.

All cases were primary and none of them had previously undergone a procedure for hypospadias repair,the mean of age of Snodgrass group is $7.1 \pm 3.62$ (to 17 years in ages) and $6 \pm 4.3$ (2 to 23 years) in modified Snodgrass group.

Table (1): Mean of age.

\begin{tabular}{ccc}
\hline & Snodgrass $(\mathrm{n}=15)$ & M.Snodgrass $(\mathrm{n}=50)$ \\
\hline Age & $7.1 \pm 3.6$ & $6 \pm 4.3$ \\
\hline
\end{tabular}

In the Snodgrass group, the technique was performed as following:

Operative steps:

Following general and caudal anesthesia and administration of a prophylactic broad-spectrum antibiotic, A silicon 8-12 Fr. Catheter is introduced into the urethra and rubber tourniquet is applied till the end of urethroplasty or maximum of 45 minutes, the time of operation is calculated from the time of application of tourniquet till closure of the glanular flap and shaft skin, it ranged from 4570 minute. Skin incisions are marked to the tissue with a fine knife blade size (15). Parallel longitudinal incisions are made deep into the glans tissue from the urethral meatus to the tip of the glans, A transverse incision proximal to the meatus is then marked and carried circumferentially, but it is otherwise in closer proximity and parallel to the corona and the penile shaft skin is degloved. A longitudinal midline incision on the urethral plate from the dorsal aspect of the urethral meatus to the glans tip is marked. This incision is carried deeply, dividing all transverse webs and exposing the underlying corporal bodies. The incised urethral plate is tubularized without tension over 8-12 Fr. Silicon catheter. A larger catheter may be used in older patients in whom a neourethra of larger luminal diameter is appropriate. Closure with a continuous single layer $6 / 0$ polyglactin suture was used in all cases for neourethral closure. The neourethra must not be closed too tightly at its distal extend. This assures adequate meatal caliber and decreases the risk for meatal stenosis. The neourethra is covered with a layer of subcutaneous tissue. The dorsal prepuce is unfolded and the underlying dartos layer is sharply dissected to the base of the penis and then incised longitudinally in the midline. One side of the flap or alternatively, a dartos flap from the lateral penile shaft skin is then brought around to the ventral aspect of the penis and is secured over the neourethra with simple, interrupted, $6 / 0$ polyglactin suture. In previously circumcised patient, in whom no valid prepuce, a local de-epithelialized lateral and/or ventral penile shaft skin must be mobilized as the source of a subcutaneous tissue flap and for penile shaft skin coverage. Adequate mobilization of the glans wings is assured such that their approximation over the neourethra is without tension with $5 / 0$ polyglactin mattress suture. The skin of the glans is then closed with a fine absorbable suture using a vertical mattress or simple techniques and the meatus is fashioned by simple interrupted suture approximation of the distal extent of the neourethra and the glans skin.

A gauze dressing was applied, rapped around the penis and fixed to it using the stay suture as well as sticky tape. The dressing was removed on the $4^{\text {th }}$ day after the operation; the catheter was removed on the $7^{\text {th }}$ day after operation.

In the modified snodgrass, the technique was performed as following:

\section{Operative steps:}

Following general and caudal anesthesia and administration of a prophylactic broad-spectrum antibiotic, A Silicon 8-12 Fr is according to the age. Catheter is introduced into the urethra, skin incisions are marked to the tissue with a fine knife blade size (15). Parallel longitudinal incisions are made deep into the glans tissue from the urethral meatus to the tip of the glans, the tow longitudinal incisions are calculated as the radial of circle on each side of the catheter (according to the size of catheter diameter) as in Fig. (2). A transverse incision immediate proximal to the meatus is then 
marked and carried connecting the tow longitudinal incisions together, a longitudinal midline incision on the urethral plate from the dorsal aspect of the urethral meatus to the glans tip is marked. This incision is carried deeply, dividing all transverse webs and exposing the underlying corporal bodies. The incised urethral plate is tubularized without tension over Silicon catheter. Closure with a continuous single layer $6 / 0$ polyglactin suture was used in all cases for neourethral closure. Then we turn to the penile dorsal and cut transversally on the penile skin proximal to the coronal sulcus at the same level of the transvers incision on the ventral aspect. After that we degloved the penile shaft and doing good hemostasis by diathermy, then rotate the prepuce anteriorly to ventral aspect (clockwise direction or anti clock wise) according to median raphe deviation after excision the most distal points of external preputial skin (dog ear) as in Fig. (2c) and suture the dorsal prepuce ventrally to the lateral edge of the previous incision to cover than take the first stitch bypolyglactin suture (vicryl 6/0) at the tip of longitudinal incision lateral to the new urethra and complete the stitches below it, after that take the stitches at the opposite longitudinal incision, then complete the stitches circumferentially below coronal sulcus, then dressing are placed on the penile shaft by betadine ointment, betadine gauze and compress it by sterile gauze and plaster, and fix the penis and catheter on abdomen by plaster, the dressing and catheter are removed after (10) days if there is no any complication happened as catheter abstraction.
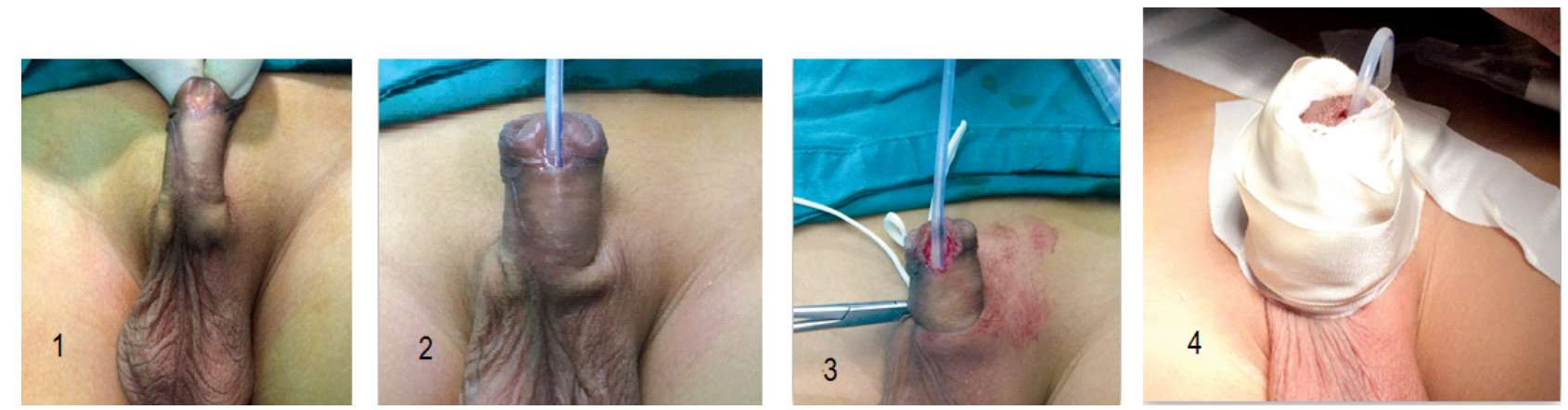

Fig. (1): Snodgrass technique: 1- Pre-operative. 2- Catheter insertion. 3- U shaped incision. 4- Dressing after complete reconstruction.
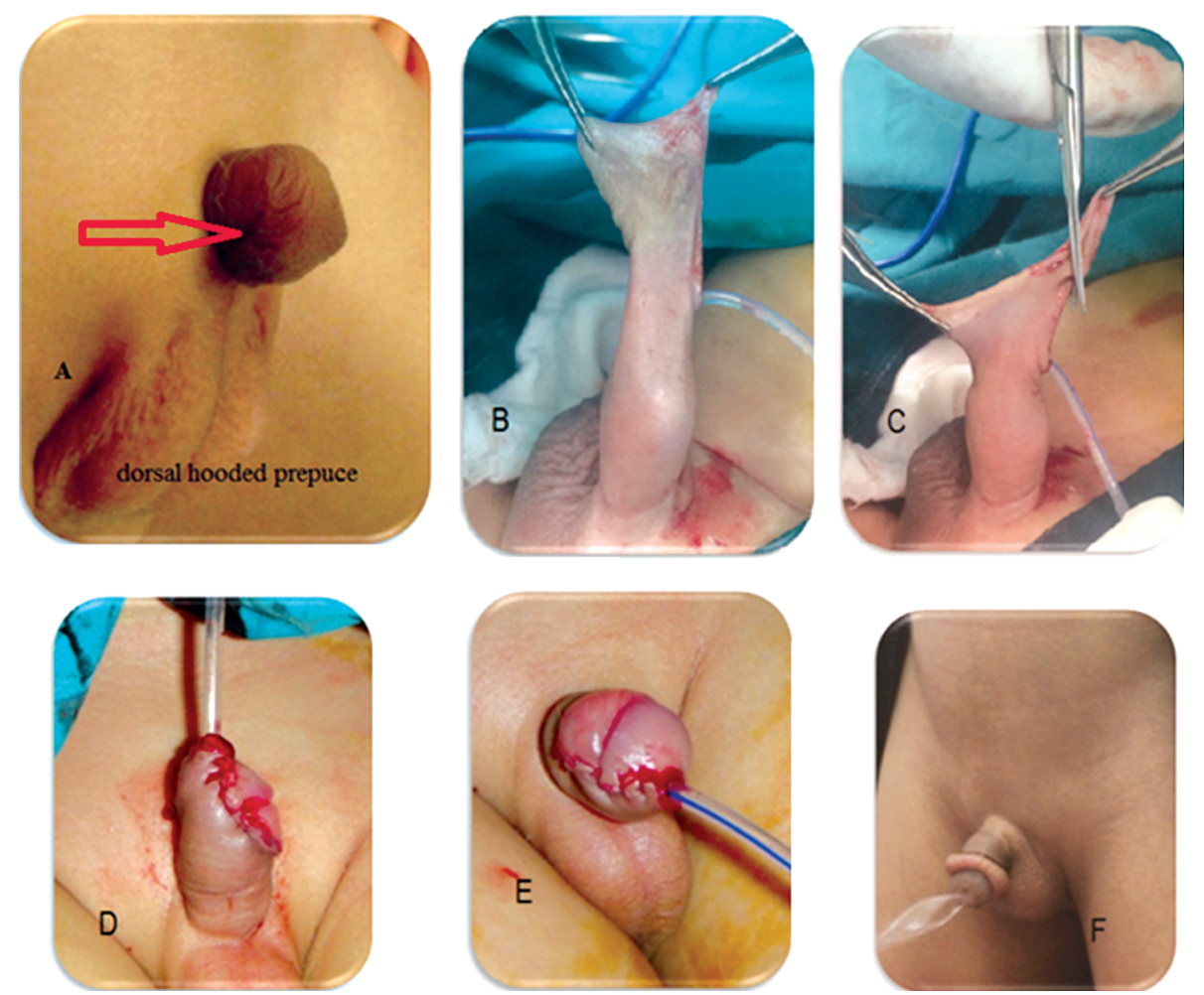

Fig. (2): Modified snodgrass technique: A- Dorsal hooded prepuce, B- Before excision distal part of prepuce, C- Excision of dog ear, D,E- Complete rotation of prepuce and stitches. 
Our new protocol to lower the incidence of hypospadias fistula in prospective study:

Pre-operative:

- The child is admitted and conformed fit for general anesthesia. (Age, Weight, Nourished, Complete Blood Count, Pediatric Examination).

- An enema is given the evening before the operation to clear the bowel as most urinary leakage within a few days of the operation.

- It may also be useful to start the child on lactulose for the first few days to avoid constipation and allow soft stooling.

- Cleanliness of the penile and scrotal area may be necessary.

\section{Intra-operative:}

- Proper design new ureteral flap dimension (length, width, anastomosisand new meatus).

- Nature and caliper catheter (Using suitable size of silicon catheteraccording to the age).

- Catheter fixation to avoid cut-throgh the wound.

- Magnification.

- Plane of flap dissection.

- Manipulation of tissue during dissection.

- Suturing the urethra on the catheter without any tension (cover the neourethra by prepuce flap and stitch it to glanular wings to avoid tension).

- Type and nature of polyglactin suture (vicryl 0.6).

- Try to close the outer skin away from urethral suture as much as you can also without any tension (using prepuce flap as in modified Snodgrass technique).

\section{Medical treatment:}

A broad spectrum antibiotics and analgesic were given, for few days after the operation. The

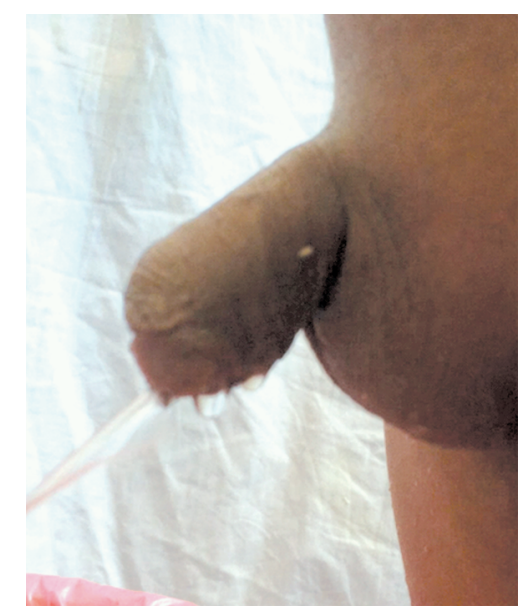

Fig. (3): Fistula complication. patient is kept on high fluid intake to prevent obstruction of the catheter.

\section{Post-operative:}

- Medication avoids post-operative edema.

- Avoid post-operative obstruction of catheter (Repeated catheter wash to prevent catheter blockage caused by Cristal or salt precipitation due to inadequate hydration).

- Post-operative dressing.

- Timing to remove the catheter (The dressing and catheter are removed after (10) days if there is no any complication happened as catheter abstraction.

\section{Follow-up:}

The patients were followed-up in the outpatient clinic as follow:

- The patients were discharged one week postoperatively.

- Patients were examined in the outpatient clinic every week during the first two months and every two weeks for four months.

\section{RESULTS}

The majority of cases ( $\mathrm{n}=50$ patient,76.23\%) have undergone modified Snodgrass technique and $(\mathrm{n}=15$ patients, $23.07 \%)$ have undergone Snodgrass technique.

Four patients $(6.15 \%)$ had developed urethrocutaneous fistula from the total of cases, and fistula complication and the other complication in modified Snodgrass group (our protocol) was better than Snodgrass group as the follow: $(n=2$ patients $4 \%)$ in modified Snodgrass group and $(\mathrm{n}=2$ patients $13.3 \%$ ) in Snodgrass group.

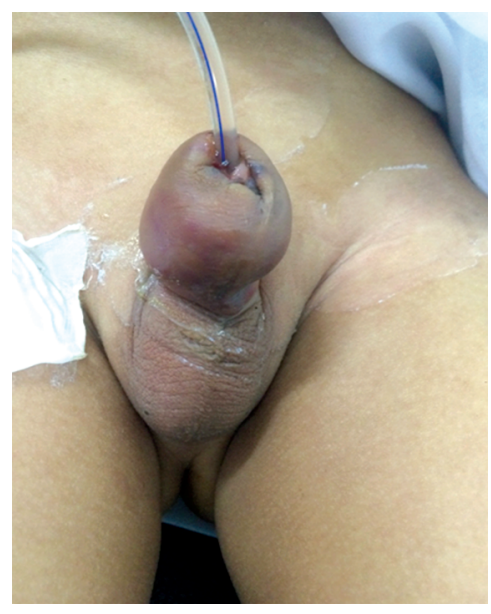

Fig. (4): Edema complication. 
The complication in modified Snodgrass was lower than Snodgrass group (Table 2).

Table (2): Complication after repair.

\begin{tabular}{llc}
\hline Complications & $\begin{array}{c}\text { Snodgrass } \\
(\mathrm{n}=15)\end{array}$ & $\begin{array}{c}\text { M.Snodgrass } \\
(\mathrm{n}=50)\end{array}$ \\
\hline Edema & $\mathrm{n}=2(13.3 \%)$ & $\mathrm{n}=1(2 \%)$ \\
Hemorrhage & $\mathrm{n}=1(6.7 \%)$ & $\mathrm{n}=0(0 \%)$ \\
Infection & $\mathrm{n}=2(13.3 \%)$ & $\mathrm{n}=0(0 \%)$ \\
Catheter obstruction & $\mathrm{n}=2(13.3 \%)$ & $\mathrm{n}=0(0 \%)$ \\
Meatal stenosis & $\mathrm{n}=2(13.3 \%)$ & $\mathrm{n}=1(2 \%)$ \\
Fistula formation & $\mathrm{n}=2(13.3 \%)$ & $\mathrm{n}=2(4 \%)$ \\
\hline
\end{tabular}

\section{DISCUSSION}

Complications after any surgical procedures are possible and these are higher in hypospadias surgery as compared to other reconstructive operations. The reported incidence of complications range from $6 \%$ to $30 \%$ varying with the severity of hypospadias [12,13].

Hypospadias repair require delicate handling of loose and fragile tissue susceptible to edema and infection. Complications depend on the type of hypospadias, surgical technique, size of the penis, age of the child, and experience of the operation surgeon. Plate preservation procedures like tubularized incised plate (TIP) is the procedure of choice in both proximal and distal hypospadias. Fistula and flap necrosis rates lower and the surgery more convenient with Snodgrass urethroplasty, with better cosmetic outcome then Mathieu repair [14].

The TIP results are better as compared to onlay flap, both functional as will as cosmetic, Inner prepucial tub repair is technically more demanding and complications are more as compared to onlay flap repair $[\mathbf{1 5 , 1 6 ]}$.

Beginning of fistula formation occurs early in the healing process after ventral urethral repair. Incorporation of urethral mucosa in the ventral repair is a substrate for fistula formation with rapid migration of urethral mucosa and skin epithelium into suture tracts. Whether the mucosal or dermal migration along suture tracts can be attenuated or prevented by changing the biochemical environment awaits further investigation [17].

Incidence of fistula varies from $0 \%$ [18] to $23 \%$ [16]. Incidence of fistula is less in urethral plate preservation procedures like TIP and onlay flap as compared to inner prepucial flap and tube urethroplasty [19].
The causes of fistula remain unknown although it is likely that local infection, local ischemia and an inadequate procedure, poor tissue healing, and distal obstruction due to meatal stenosis. Anatomical factor like severity of hypospadias and satisfaction of surgeon after surgery has significant impact on the outcome of surgery. Local anatomical factors and urine leakage emerge as strong factors for fistula formation and local infection as moderate risk factor [20].

In our study four patients $(6.15 \%)$ had developed urethrocutaneous fistula from the total of cases, and fistula rate in modified Snodgrass group was lower than Snodgrass group as the follow: $(\mathrm{n}=2$ patients $4 \%)$ in modified Snodgrass group and $(\mathrm{n}=2$ patients $13.3 \%)$ in Snodgrass group.

Other complications was developed in our study as edema one case in our protocol (Modified Snodgrass) and developed fistula after that, $2 \%$, and 2 cases $13.3 \%$ in snodgrass group and one case are develop the fistula after edema complication.

Infection complications was developed two cases $13.3 \%$ in Snodgrass group and one of these cases developed fistula.

\section{Conclusion:}

In our study the complications edema, infection, hemorrhage, catheter obstruction and fistula formation in modified Snodgrass group (our protocol) was less than Snodgrass group.

Modified Snodgrass group (our protocol) is better than the Snodgrass group to lowering the rate of fistula complication.

\section{REFERENCES}

1- Baskin L.S. and Ebbers M.B.: Hypospadias: Anatomy, etiology, and technique. J. Pediatr. Surg., 41: 463-72, 2006.

2- Leung A.R.C., Robson W.L.M.: Hypospadias: An update. Asian J. Androl., 9: 16-22, 2007.

3- Johnson and Coleman D.J.: Use of singel and two stage technique for hypospadias correction. Br. J. Plast., 51 (3): 195-201, 1998.

4- Cook A., Khoury A.E., Neville C., Farhat W.A. and Pippi Salle J.L.: A multicenter evaluation of technical preferences for primary hypospadias repair. J. Urol., 174: 2354-7, 2005.

5- Hayashi Y. and Kojima Y.: Current concepts in hypospadias surgery. Int. J. Urology, 15: 651-63, 2008.

6- Kirkali Z.: Tunica vaginalis. An aid in hypospadias surgery. Br. J. Uro., 65: 530, 1990. 
7- Snodgrass W.: Tubularized, incised plate urethroplasty for distal hypospadias repair. J. Urol., 151: 464-465, 1994.

8- Snodgrass W., Koyle M., Manzoni G., Horowitz R., Caldamone A. and Ehrlich R.: Tubularized incised plate hypospadias repair: Results of a multicenter experience. J. Urol., 156: 839-841, 1996.

9- Steckler R.E. and Zaontz M.R.: Stent-free ThierschDuplay hypospadias repair with the Snodgrass modification. J. Urol., 158 (3 Pt 2): 1178-1180, 1997.

10- Baskin L.: Hypospadias. A Critical Analysis of Cosmetic Outcomes Using Photography. BJU International, 87: 534-9, 2001.

11- Yutaro H., Yoshiyuki K., Satoshi K., Kentaro M., Akihiro N. and Kenjiro K.: Scrotal dartos flap for the prevention of the urethrocutaneous Fistula on hypospadias urethroplasty, Int. J. Urol., 12: 280, 2005.

12- Duckett J.W.: Hypospadias. In; Walsh P.C., et al., editors. Campbell's Urology. $7^{\text {th }}$ ed. Philadelphia: WB Saunders Co, Pp. 2093-119, 1998.

13- Beuke M. and Fisch M.: Salvage strategies after complication of hypospadias repair. Urologe A, 46: 167-5, 2007.

14- Snodgrass W.T. and Lorenzo A.: Tubularized incised- plate urethroplasty for hypospadias reoperation. Br. J. Urol. Int., 89: 89-100, 2002.

15- Njinou B., Terryn F., Lorge F., Opsomer R.J., DeGroote P., Veyekemans F., et al.: Correction of sever median hypospadias: Review of 77 cases treated by the onlay island flap technique. Acta. Urol. Int., 84: 89-94, 1999.

16- Elbarky A.: Complications of the preputial island flaptube urethroplasty. Br. J. Urol. Int., 84: 89-94, 1999.

17- Edney M.T., Lopes J.F., Ellsworth P.I. and Cendron M.: Time course and histology of urethrocutaneous fistula formation in a porcine model of urethral healing Eur. Urol., 45: 806-10, 2004.

18- Kass E.J. and Bolong D.: Single stage hypospadias reconstruction without fistula. J. Urol., 144: 520-2, 1990.

19- Uygur M.C., Unal D., Tan M.O., Germiyanoglu C. and Erol D.: Factors affecting outcome of one-stage anterior hypospadias repair. Analysis of 422 cases. Pediatr. Surg. Int., 18: 142-6, 2002.

20- Ratan S.K., Sen A., Pandey R.M., Hans C., Roychaudhary S. and Ratan J.: Lesser evaluated determinants of fistula formation in children with hypospadias. Int. J. Clin. Pract., 55: 96-9, 2001 